\title{
The Main Problems and the Role of Teachers in the Transformation of Education in Serbia
}

\author{
Marko Atlagic \\ The University of Mitrovica, Faculty of Philosophy, Serbia; atlagicmarko@gmail.com
}

Zvezdana Elezovic

Institute of Serbian Culture Leposavic, Serbia; zvezdana.el@gmail.com

Vesna Minic

The University of Mitrovica, The Faculty of Teacher Education, Serbia; vesna.minic@pr.ac.rs

\section{Doi:10.5901/mjss.2016.v7n5p138}

\section{Abstract}

This paper discusses the issue of the reform of education in the Republic of Serbia, which should be carried out on democratic grounds. The authors advocate the transformation of the entire education system on democratic grounds. The reform has to be fast, thorough, and democratic. The teacher has to play the central role in this strategic plan. Therefore, the role of the teacher should be transformed from an indifferent or authoritarian teacher into one with a democratic approach, who will cooperate with students in the planning, execution, and implementation of the educational process. For this role of teachers, it is necessary to utmostly improve his/her professional and pedagogical development.

Keywords: education, teacher, pedagogue, reform

\section{Introduction}

In the past half century, many reforms have come and gone. Each of them left, among other things, a positive sign, brought changes, but there has been only few reforms whose strategy was carefully designed, and even a smaller number of those that were fully implemented. None of them has been able to be, in a true sense, democratic, educational, and scientifically based (Strategy, 2012). Moreover, no reform, to date, has managed to solve the problem of adequate financing of this very important activity. Regardless of it, education has become, more or less, a generator of the progressive development of society (Pastuovic, 2012).

Pedagogical sciences were late, and are late today as well, in providing answers to many open pedagogical questions, both those from the domain of the concept of the education system, and those within the scope of its internal organization. Therefore, the reform of education must be entered into democratically, scientifically based, and very courageously, and without hesitation. The reform must be democratic, radical, and comprehensive. In the first phase of implementation, the reform should include faculties of education and other faculties. Then economic and educational prerequisites should gradually be created for a reaffirmation of the educational role of the school and society, especially the pedagogical profession, which has been neglected in the last two decades in the Serbian society. The pedagogical institutes and faculties of education should not be excluded from making the concept and implementing the reform of education. Never has it been more necessary than today to face the social and pedagogical reality, to critically reexamine our experiences, without any overestimation or underestimation of any model of education. Never has it been more necessary than today to affirm the system of permanent professional and pedagogical training of education workers (Exposé, 2014). First of all, we need a rebellion of truth about the state of Serbian educational system, because we can no longer leave students on an educational astray.

\section{Method}

Our research on the subject of this scientific work belongs to the fundamental or basic research dealing with the study of 
fundamental problems in the educational process; phenomena in this area are determined by it. Therefore, it was necessary to use certain knowledge along with scientific methods in order to reach scientific results. This refers to education reforms, the role of teachers in the educational process, and other issues. The aim of our study was to show basic issues regarding the role of teachers in the education reform in Serbia. In the study, we have used general scientific methods that are applied directly or indirectly in all social sciences and scientific disciplines, hypothetico-deductive method, and analytic-deductive method. In the research, the method for document analysis, which is an empirical research method, has been unavoidable, and also the method of theoretical research. Every modern scientific research begins by applying this method, because at the very beginning of conceptualization, it addresses the scientific foundation - therefore, begins to research it by using the method of (content) analysis of documents. In this manner, we have conducted an analysis of the most important documents relating to the issue of the education reform in Serbia (Exposé, Strategy, etc.). We have also used the historical method as a method to study the issues in education from the past, that is, interpretations of the relevant scientific literature on this issue.

\section{Results and Discussion}

Education is the primary resource of a society, especially of a society in transition, such as the Serbian society. Therefore, it can contribute to the overall socio-economic progress if all necessary prerequisites for its modern functioning are created. As a particular scientific significance of our research, we would like to emphasize the interpretation of key government documents relating to the reform of education in Serbia. This primarily refers to the parts of the exposé of the Prime Minister of Serbia, which are related to the education reform and the Education Reform Strategy adopted by the Serbian Parliament. These documents, as sources for the study of the education reform, have not been used in science until now, as evidenced by the latest scientific literature on this issue, in which these documents are not mentioned. Thus, the collection of scientific papers of around a thousand pages (Jovanovic, Vilotijevic, 2014), from the greatest conference that has been held on this issue in Serbia, does not discuss these documents.

Thus, the reform of the education system is a key prerequisite and an imperative of the modernization project of Serbia (Ibid). To perform the transformation of education based on modern pedagogical grounds, it is necessary to:

1. Take measures to, based on the Strategy for Development of Education in Serbia by 2020, draw up an Action Plan of Measures for Implementation of Each Strategy Task.

2. Urgently perceive the state of the staffing issues in educational institutions and present it to the wider public, and the state has, in recent years, been deteriorating severely, with a drastic decline in the quality of pedagogical work and frequent violations of pedagogical and legal norms.

3. The Ministry of Education, Science and Technological Development, as a minimum of prerequisites for responsible performing of significant social and educational functions in their departments and agencies, should have competent educational experts: pedagogues, class teachers, educators, and other necessary class experts who have majored in or studied pedagogy as part of their curriculum.

4. It is necessary to urgently analyze the pedagogical and professional training of education workers, save it from a deep and dangerous crisis, a general chaos, improvisation, commercialization, volunteering, amateurs, psychologization, politicization, a waste of resources and time, to suspend the implementation of all programs and projects of non-governmental organizations until they receive a pedagogical verification (Milijevic, 2002).

5. It is necessary to treat the process of accreditation of programs and faculties as a first-class national task that should resolutely perform a modern educational function of these pedagogical institutions, defending students from further decline in the reputation and quality of teachers' work (HAA, 2011, Accreditation, 2007).

6. It is necessary to urgently adopt a new law on higher education (not amendments as now), because the teaching practice has shown disastrous results of a rushed and non-pedagogical "Bolognization" of Serbian universities, and this law has officially recognized both the imposed practice of lowering the quality of studies and wasteful spending of funds, while studying is becoming less and less available to the poor (Law, 2005).

7. It is necessary to abolish descriptive assessment of students in lower grades of elementary school. Descriptive assessment of students existed in Serbian school system more than three decades ago, and it was rejected by the teaching practice as an administrative absurd and a waste of teachers' time. A person who knows at least a little bit about educational psychology and child psychology can understand how much a grade in the form of a number is important for children, while a descriptive assessment cannot avoid clichés, molds, phrases in the "description of knowledge" of students. Therefore, it should be abolished immediately and sent to the educational history (Jovanovic, 2010). Grading of students in schools and universities should be radically innovated, didactically molded, organizationally and pedagogically improved, with the utmost responsibility of 
teachers for the success of their students, all "scary teachers" who do not know the students who attend their classes should be moved away from the educational process. The schools and universities of the future, in the normal organizational and technical and pedagogical conditions, and with true teaching professionals at the cathedra, have to lead all the students to the desired success (Gojkov, 1997).

8. Analyze the appropriateness of entrance examination for admission to secondary schools and faculties, consider the possibility to abolish entrance examination and meaningless matriculation examination, because they spend an enormous amount of time and financial resources, create a dramatic non-educational atmosphere, in which we are not sure whether the results achieved are objectively the state of knowledge and abilities of our students (Wrightstone, Justman, Robbins, 1966).

9. Special education is in a very serious condition; the problems in this area are being studied by various "imported products," false humanitarians, and non-pedagogical and inhuman projects of the so-called inclusive education. It is therefore necessary to analyze the situation as soon as possible, to discover the causes of failure and take appropriate measures, otherwise it could lead to dramatic pedagogical consequences for children, parents, and the society as a whole (Radivojevic, 2007; Hrnjica, 1991).

10. In the system of education, special attention should be paid to pedagogy (teaching) faculties, so it is necessary to comprehensively ponder the current development, the current practice of these institutions, relieve them of many irrational concepts and solutions that have survived. Study plans and programs have to be uniform throughout the entire territory of the Republic of Serbia, without excessive and pointless electives (Vuckovic, 2000).

11. Restore the reputation of students' extracurricular activities. The time of transition has, among other things, led to a dramatic decline in the system of students' extracurricular activities, which have an outstanding educational nature, foster creativity, and contribute to the humanization and socialization of relationships in students (Jovanovic, 2004).

12. Critically review the "School without Violence" action, as such actions have achieved almost nothing. The Ministry of Education and Science should approach this issue in a very responsible manner. They should include this project in their program, but without relying on non-governmental organizations and overly on psychologists, because psychologists are increasingly turning to and dealing with the consequences of violence (which is their task), instead of discovering the causes and proposing educational measures to eliminate the causes that have led to violence (which is a task of pedagogues). Therefore, school pedagogues should be more and more involved in this "game," since it is their main task, because they are professionally and pedagogically trained for this job (Ferencic, 2007).

13. Radio Television of Serbia (public broadcaster) should innovate a reintroduction of "educational program" to its editorial policy and "scheme," which had been for decades one of the best in the European area. Without a pedagogical dimension, this medium cannot bear the "title" of the public broadcaster (Radovic-Jovanovic, 2010).

14. It is necessary to pay more attention to the "campaign" of IT education of pedagogical workers, which would be a great and rational step towards the modernization of educational work in general (Lapcevic, 2000).

15. To reclaim the reputation of teachers. Today it is the hardest to be a teacher, and often unappreciated and precarious, because:

a) the teacher does not have the necessary freedom nor the respect for the value of their profession;

b) the authorities do not want to know what teachers think and propose in education, what they suffer and with what they are dissatisfied;

c) the working conditions of teachers are unfavorable (an overload of standard hours, an unfavorable sociomental climate for the evaluation of their work, and even rewarding is not at an adequate level);

d) there is a lack of good-quality, competent, professional training of all education workers, teachers in particular, and instead, improvisation in work is being forced upon through "workshops" and "playgroups" and all sorts of accreditations of a commercial nature (Brophy, Good, 1988);

e) radio and television are to a large extent the opposite of what is taught in schools and what the teacher has to achieve in the classroom (Williams, Bruden, 1997);

f) the curricula and teaching methods on teacher training faculties are outdated, so teachers are not sufficiently trained for complex pedagogical and methodological actions and commitments;

g) today many people who are unprofessional and incompetent for teaching discuss pedagogical issues, and these people often share lessons from the small screen and "tailor" educational standards.

The teacher at the cathedra (Bratonic, 1993), both in rich and poor countries, has been and remains in the shadow 
of the more skillful, more audacious, more rapacious, more amoral, small-minded thieves of his/her merits and earnings. The struggle for freedom of the teaching profession is eternal, as well as the fight for the freedom of every man (Latic, 2001), since pedagogy is a science about democracy and freedom. The teacher has always paid dearly his/her mission and worth in the grip of political struggle and changes. The history of teaching mission has always been, and it is today, the history of continuous struggle for a free teacher, a free school and a free educatee. In the grip of bureaucratic and political "machines," the teacher has always been tempted: to be or not to be an authentic guide of a Prometheus' caliber to both the estimates of the culture of good and evil, the culture of knowledge and ignorance, honesty and dishonesty (Laketa, 1998).

The question is raised of whether the state should protect teachers in the Serbian education system from various negative impacts, professions coming out of school (Matanovic, 2009). The theft of the teaching pedagogical profession has unofficially been legalized, as well as the enrichment of mentioned nonprofessionals in the collapse of the teaching profession in the 21st century (Matijevic, 2003).

On the other hand, today, there are three basic types of teachers in Serbian schools:

1. Authoritative type of teachers. It is a teacher who mainly requests from students to blindly obey him/her, that they cannot do absolutely anything without him/her. The teacher requests absolute obedience, exercising power over students.

2. Indifferent type of teachers. He/she is generally uninterested in the work of students. The teacher is a passive observer of the students' work, and allows for students to have complete freedom in decision-making. Students can do whatever they want (Djordjevic, 2004).

3. Democratic type of teacher. Such a teacher communicates with students and uses democratic means of communication. He/she respects and appreciates students, and students respect him/her. The teacher does not request blind obedience from students, and he/she is not indifferent, instead he/she collaborates with students, makes arrangements, coordinates and animates them. He/she accepts suggestions and proposals of students regarding the teaching process and directs it towards the interests of the students (Krnjajic, 2002).

\section{Conclusion}

The role of the teacher is extremely important in the transformation of education in Serbia. The fact that the state policy of Serbia is directed towards efforts to help the education sector and to carry out its reform in the best way is of great importance. It is also very important which of the three types of teachers will prevail in Serbian schools, which depends on many factors, both within schools and universities, and outside them. Primarily, the school has to be an educational institution designed upon modern pedagogical principles and work organization, thus, in most of them, the democratic type of teachers will be the most dominant and the most acceptable, both for students and parents, and for the community as a whole.

\section{References}

(2007): Accreditation in Higher Education. Belgrade: Ministry of Education and Sports.

(2012): Family, Adolescence, Transition. Belgrade: Serbian Academy of Science and Arts (SANU).

(2014): Prime Minister of the Republic of Serbia Aleksandar Vucic: Framework Exposé. Belgrade.

(2014): The Strategy for Development of Education in Serbia by 2020. Belgrade: Government of the Republic of Serbia.

(2011): Croatian Accreditation Commission. The rules for the accreditation of bodies for assessment of conformity. Pr - 2/4. Zagreb: thirteenth edition.

Bratanic, M. (1993): Macro Pedagogy. Zagreb: SKK.

Brophy, J., Good, T. (1986): Teacher behavior and student achievement. In M. C. Wittrock (Ed.), Handbook of research on teaching, 3, 328-375

Williams, M. (1997): Psychology for Language Teachers. Cambridge University Press.

Vuckovic, V. (2000): Determinants of educational achievements of students of the Faculty of Education. Jagodina: Faculty of Education. Gojkov, G. (1997): Docimology. Belgrade: Faculty of Education.

Djordjevic, J. (2004): Teaching as a process of giving instruction, learning and communication. Communication and Media. Jagodina Faculty of Education.

Jovanovic, B., Vilotijević, M. (2014): The Role of Education in the Development of Humanistic, Intercultural and National Values: thematic collection of papers of international significance. K. Mitrovica: Faculty of Philosophy.

Jovanovic, B. (2004): The school and education. Jagodina: Faculty of Education.

Jovanovic, M. (2010): Descriptive evaluation to humanization of teaching. Proceedings of Education for Humane Relations - Problems and Prospects. Nis: Faculty of Philosophy, 135-136. 
Krnjajic, S. (2002): Social relations and education. Belgrade: Institute and Educational Research.

Laketa, N. (1998): Teacher in elementary school - teacher in high school - student. Uzice: Faculty of Education.

Lapcevic, Z. (2000): Teachers Manual. Belgrade: Eduka.

Latic, M. (2001). Pedagogical humanism in the teacher - student relation. Banja Luka: Neo.

Mandic, P. (1980). Humanization of relations at school. Sarajevo: PPZ.

Matanovic, J. (2009): Personality traits as predictors of job satisfaction. Applied Pedagogy, 2, 3, 327-338.

Matijevic, M. (2003): To research and publish: the elements of methodological literacy in pedagogy. Zagreb: HKPZ.

Milijevic, S. (2002): The continuous professional development of teachers in the function of educational work improvement. Our school, $1-2,183-204$

Pastuovic, N. (2012): Education and development: how education develops people and changes society, and how society influences education. Zagreb: Institute for Social Research, Faculty of Education.

Petrovic, S. (1995): School and personality development of students, Proceedings, 199-209.

Radivojevic, D. (2007): A Guide for Advancement of Inclusive Educational Practice. Belgrade: Fund for an Open Society.

Wrightstone, W. Justman, J. Robbins, I. (1966): Evaluation in Modern Education. Belgrade, Vuk Karadzic.

Suzic, N. (2003): Teachers' characteristics and students' attitudes towards teaching. Banja Luka: Teacher Education Center.

Ferencic, S. (2007): Prevention of domestic violence. Zagreb: Women's Help Now.

Filipovic, S. (2011). Methodology of art education. Belgrade: University of Arts.

Hrnjica, S. (1991): A child with developmental difficulties. Belgrade: Institute for textbooks.

Siljkovic, G. Rajic, V. Bertic, D. (2007): Extracurricular Activities. Educational Sciences, 9, 133-145. 